\title{
Hanseníase virchowiana em cardiopata chagásico: relato de necropsia
}

\author{
Generalized hanseniasis in Chagas' myocardiopathy: \\ necropsy study \\ Marcus Aurelho de lima, Virmondes Rodrigues Junior, Mario León \\ Silva-Vergara, Mario Betônio Nomelini, Neivo Paim, \\ Taciana Arruda Modesto dos Sontos e Vitorino Modesto dos Santos
}

Resumo Relata-se caso de hanseníase virchowiana diagnosticada à necropsia, com alterações cardíacas causadas diretamente por micobactérias, em homem de 34 anos portador de miocardiopatia crônica chagásica. Enfatiza-se o possivel papel de mediadores inflamatórios na gênese da disfunção miocárdica; bem como a possibilidade de que fatores associados à insuficiência cardíaca, como esplenomegalia congestiva e infartos esplênicos, possam causar imunodepressão, predispondo à infecção generalizada.

Palavras-chaves: Hanseníase virchowiana. Doença de Chagas. Miocardite. Imunodepressão. Necropsia.

Abstract This is a case report of lepromatous infection diagnosed at necropsy, with cardiac alterations directly caused by mycobacteria, in a 34-year old black male with the cardiac form of Chagas' disease. The possible role of inflammatory mediators on cardiac dysfunction, and the possibility that immunedepression may be due to factors associated with heart failure, as congestive splenomegaly and splenic infarctions, are emphasized.

Key-words: Lepromatous hanseniasis. Chagas' disease. Heart failure. Immunedepression. Necropsy.

Disciplina de Patologia Especial, Curso de Pós-graduação em Patologia Humana e Departamento de Clínica Médica do Hospital Escola da Faculdade de Medicina do Triângulo Mineiro, Uberaba, MG.

Endereço para correspondência: Prof. Vitorino Modesto dos Santos. Alameda da República, 64. Recanto das Torres. Uberaba, MG. 38057-020.

Recebido para publicação em 18/12/97. 
Vários estudos têm demonstrado alterações da resposta imunológica $(\mathrm{RI})$ na hanseníase, sendo o grau de comprometimento do sistema imune mais acentuado na forma virchowiana. Nesta forma, há uma depressão seletiva de linfócitos T CD4+ do tipo Th1, produtores de interferon- $\gamma$ (IFN- $\gamma$ ) e fator de necrose tumoral- $\beta$ (TNF- $\beta$ ), importantes citocinas envolvidas na ativação da resposta imune celular contra patógenos intracelulares. Por outro lado, nesses pacientes, observa-se uma exacerbação da resposta de linfócitos T CD4+ do tipo Th2, produtores de interleucinas (IL) 4 e IL-5, que ativam a produção de anticorpos e ainda apresentam efeitos inibidores 61823 sobre a resposta Th1. Já em relação à doença de Chagas, estudos experimentais na sua forma crônica, apontam para o reconhecimento de autoantígenos cardíacos por linfócitos T CD4+, atribuindo assim uma participação auto-imune na gênese da miocardite 8 . Evidências experimentais indicam que durante a infecção pelo Trypanosoma cruzi, existe uma diminuição da resposta proliferativa de linfócitos, relacionada a um aumento da taxa de apoptose de linfócitos T CD4+19, sendo também conhecida a maior susceptibilidade de linfócitos Th1 à apoptose. A possibilidade que o $T$. cruzi utilize, como mecanismo de escape, a ativação preferencial da resposta Th2 já foi sugerida, contribuindo desta forma para um desbalanço das subpopulações de linfócitos T auxiliares ${ }^{8}$.

Realizamos estudo de necropsia de paciente portador de miocardiopatia chagásica crônica e hanseníase virchowiana, que faleceu por insuficiência cardíaca descompensada. O presente relato de caso visa enfatizar o papel de fatores associados à doença de Chagas no elenco de possíveis causas de imunodepressão que propiciariam a disseminação da infecção micobacteriana crônica.

\section{RELATO DO CASO}

Homem preto, 34 anos, pedreiro, procedente de Planura, MG, foi internado no Hospital Escola da Faculdade de Medicina do Triângulo Mineiro em 08/02/97, com história de astenia, anorexia, náuseas, vômitos, emagrecimento (6kg em 6 meses), placas eritematosas e pústulas pruriginosas disseminadas há 6 meses; além de palpitações, dispnéia, oligúria, edema de membros inferiores e ascite há um mês. Usava digoxina, captopril e furosemide. Relatava doença de Chagas, lombotomia direita por cálculo renal há 3 anos e tabagismo (20 cigarros/dia há 17 anos). Negava etilismo ou adição a drogas. Referia hanseníase paterna.

À internação, o estado geral era regular, apresentava dispnéia, ascite, derrame pleural e edema de membros inferiores (+++). Na pele, observavam-se manchas hipercrômicas, pústulas, lesões úlcero-crostosas e placas eritematosas

disseminadas. A temperatura axilar era de $36,7^{\circ} \mathrm{C}$. A ausculta dos pulmões revelou diminuição bilateral do murmúrio vesicular e estertores bolhosos nas bases. O exame cardiovascular demonstrou coração arrítmico, bulhas hipofonéticas, sopro sistólico (+) no foco mitral, freqüência de $100 \mathrm{bpm}$ e tensão arterial de $110 / 80 \mathrm{mmHg}$. O fígado era palpável a $10 \mathrm{~cm}$ do rebordo costal direito, doloroso e liso. A palpação do baço foi dificultada pela ascite.

Exames complementares. Hemácias $5.070 .000 / \mathrm{mm}^{3}$; hemoglobina $14,2 \mathrm{~g} / \mathrm{dl}$; hematócrito $42,1 \%$; volume corpuscular médio 83; hemoglobina corpuscular média 28; concentração da hemoglobina corpuscular média 33,7; plaquetas $146.000 / \mathrm{mm}^{3}$; leucócitos $13.000 / \mathrm{mm}^{3}$, com $90 \%$ de neutrófílos segmentados, $7 \%$ de linfócitos $\left(910 / \mathrm{mm}^{3}\right)$ e $2 \%$ de monócitos. Proteínas totais $5,3 \mathrm{~g} / \mathrm{dl}$, albumina $2,7 \mathrm{~g} / \mathrm{dl}$, globulinas $2,6 \mathrm{~g} / \mathrm{dl}$; sódio $126 \mathrm{mEq} / \mathrm{l}$; potássio $3,3 \mathrm{mEq} / \mathrm{l}$; cloro $86 \mathrm{mEq} / \mathrm{l}$; uréia $60 \mathrm{mg} / \mathrm{dl}$; creatinina $1 \mathrm{mg} / \mathrm{dl}$; glicose $57 \mathrm{mg} / \mathrm{dl}$; TGO $61 \mathrm{U} /$; TGP 28U/l. Sorologias positivas para doença de Chagas. Radiografia do tórax evidenciou cardiomegalia grau IV e derrame pleural bilateral. Eletrocardiograma revelou fibrilação atrial, extrassístoles ventriculares, bloqueio completo do ramo direito e bloqueio ânterosuperior do ramo esquerdo do feixe de His, além de zona ântero-lateral inativa e alterações difusas da repolarização ventricular.

Produto de toracocentese: 700 mililitros de líquido amarelo-citrino, $\mathrm{pH} 8,5$, densidade 1.010 , hemácias $1.600 / \mathrm{mm}^{3}$, células $160 / \mathrm{mm}^{3}$, linfócitos $84 \%$, glicose $109 \mathrm{mg} / \mathrm{dl}$, desidrogenase lática $185 \mathrm{U} / \mathrm{l}$, proteínas $1,4 \mathrm{~g} / \mathrm{dl}$ e abundantes células mesoteliais. A bacterioscopia, pelo método de Gram, a pesquisa de bacilos álcoolácido resistentes (BAAR) e a reação em cadeia da polimerase para o bacilo da tuberculose no líquido pleural foram negativas; a cultura do material foi positiva para Staphylococcus epidermidis.

Evoluiu com subnutrição protéico-calórica, sem melhora do quadro clínico, apesar do 
repouso, da dieta hipossódica e do tratamento com cloreto de potássio, furosemida, captopril, digitálico, heparina SC, metoclopramida e benzoato de benzila. $\mathrm{O}$ óbito ocorreu no $7^{\circ}$ dia de internação devido à insuficiência cardíaca refratária ao tratamento.

Dosagem de interleucinas no soro, pós morte, e sensibilidade do teste (S) em picogramas por mililitro $(\mathrm{pg} / \mathrm{ml})$ : fator de necrose tumoral alfa $(\mathrm{S}: 20)=120 \mathrm{pg} / \mathrm{ml}$; IL-4 (S: 10) $=212 \mathrm{pg} / \mathrm{ml}$; IL-10 (S:10) = 15pg/ml; não foram detectáveis o Interferon gama (S: 10$)$, a IL-1 (S: 60) e a IL-5 (S:10). A sorologia para o vírus da imunodeficiência adquirida, pelo método ELISA, foi negativa (título: $0,049 \mathrm{ng} / \mathrm{ml}$ e cut off $=0,141 \mathrm{ng} / \mathrm{ml}$ ) no sangue colhido de cavidade cardíaca.

Necropsia. Cadáver de homem de raça negra com idade aparente de 34 anos, pesando $51 \mathrm{~kg}$ e medindo $1,68 \mathrm{~m}$ (índice de massa corporal: $18,1 \mathrm{~kg} / \mathrm{m}^{2}$ ), em anasarca. Ao exame externo, apresentava lesões cutâneas máculopapulares acastanhadas difusas, algumas ulceradas, cobertas ou não por crostas. Havia sinais de venóclises nos membros superiores e cicatriz de lombotomia direita, à Ruster, medindo $12 \mathrm{~cm}$ de comprimento. Os achados fundamentais foram vistos na pele, fígado, baço, laringe, testículos e coração.

$\mathrm{Na}$ pele foram observadas lesões, algumas vezes ulceradas, com infiltrado inflamatório linfohistiocitário sem formação de granulomas acometendo as dermes papilar e reticular ao redor de filetes nervosos, anexos cutâneos e vasos sangüíneos capilares (Figura 1). Processo inflamatório linfohistiocitário semelhante acometia também o baço, fígado, laringe, testículos e

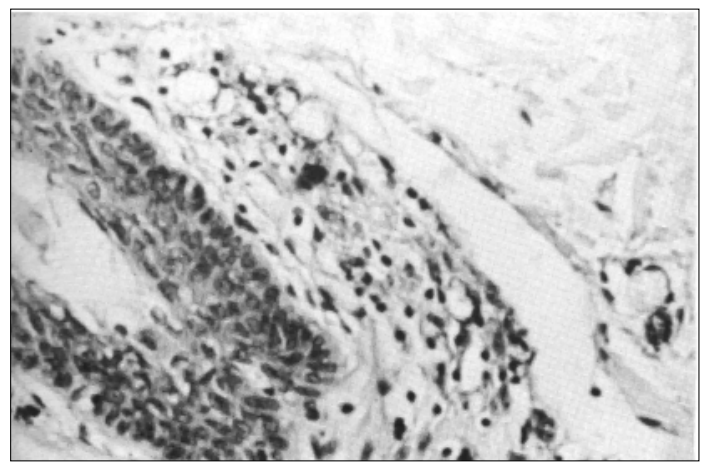

Figura 1 - Folículo piloso circundado por infiltrado inflamatório linfohistiocitário sem formação de granulomas (HE, 400x). coração com histiócitos de aspecto espumoso. A pesquisa de BAAR revelou abundante número de bacilos no interior dos histiócitos formando, muitas vezes, globias (Figura 2). O quadro foi diagnosticado como hanseníase virchowiana.

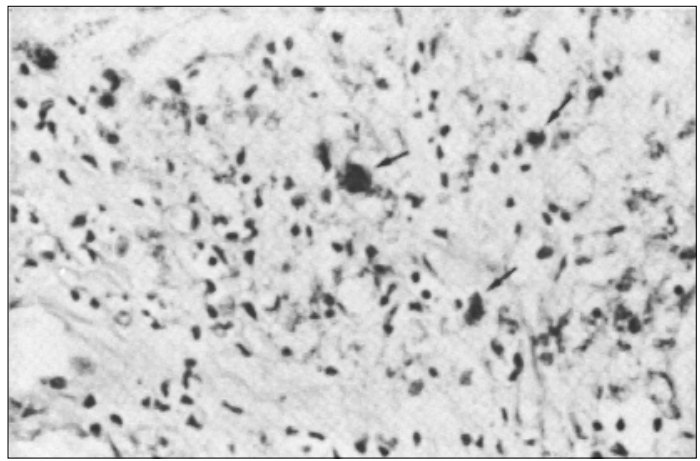

Figura 2 - Corte histológico de pele mostrando infiltrado inflamatório linfohistiocitário com abundante número de bacilos álcool-ácido resistentes formando globias (setas) no interior de histiócitos (Fite-Faraco, 400x).

O coração pesava $605 \mathrm{~g}$ e mostrava epicardite moniliforme e em placas, trombose e adelgaçamento da ponta do ventrículo esquerdo. O exame microscópico demonstrou infiltrado inflamatório linfohistiocitário endomisial, com destruição de miofibras e substituição por fibrose (Figura 3). A pesquisa de T. cruzi, pelo método imuno-histoquímico, revelou-se positiva no interior de fibras miocárdicas. Estes achados,

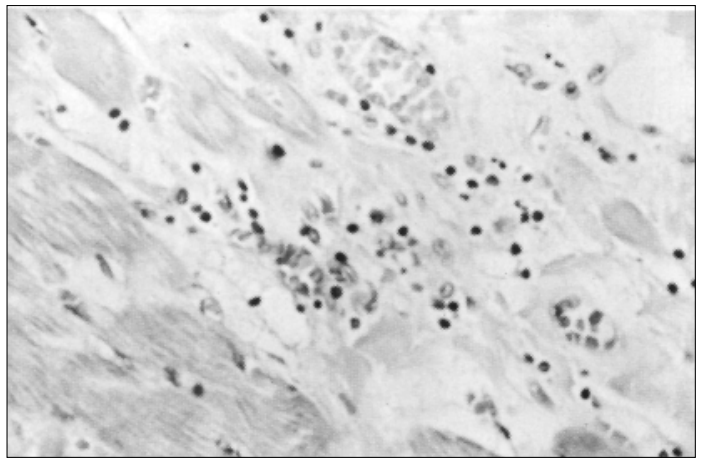

Figura 3 - Corte histológico de miocárdio mostrando infiltrado inflamatório linfohistioplasmocitário permeando e destruindo fibras musculares (HE, 400X). 
juntamente com a sorologia positiva, individualizaram o quadro como cardiopatia chagásica crônica (Figura 4). A pesquisa de

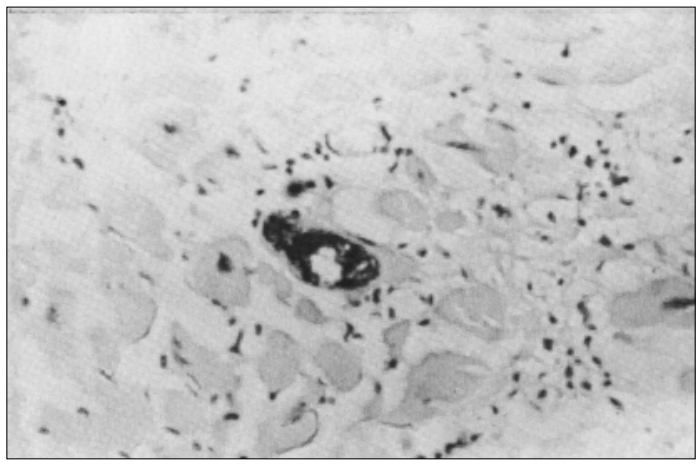

Figura 4 - Ninho de Trypanosoma cruzi no interior de fibra miocárdica (centro do campo) corado pelo método imuno-histoquímico (Peroxidase-anti-peroxidase, 400x).

Em conseqüência da insuficiência cardíaca congestiva, observou-se congestão passiva crônica do fígado e do baço, edema nos membros inferiores, hidrotórax bilateral $(1.100 \mathrm{ml})$,
BAAR mostrou-se positiva nos histiócitos espumosos que caracterizavam a miocardite associada à hanseníase (Figura 5).

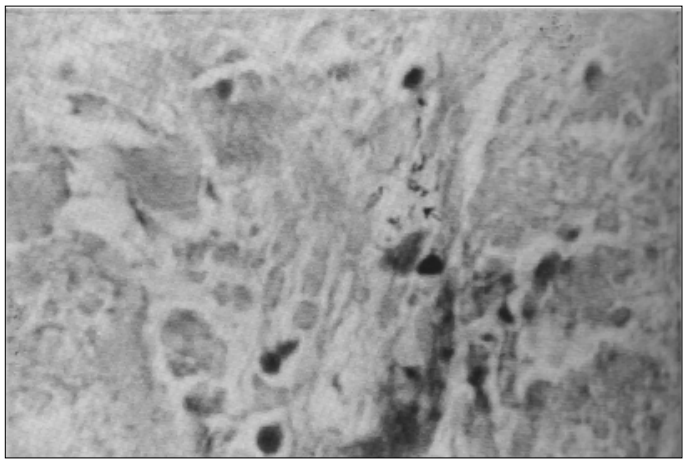

Figura 5 - Bacilos álcool-ácido resistentes (seta) no interior de histiócitos de infiltrado inflamatório que permeia fibras cardíacas (Fite-Faraco, 1000x).

hidroperitônio (1.900ml) e hidropericárdio $(120 \mathrm{ml})$. Decorrente da trombose intracardíaca com formação de êmbolos, havia infartos antigos no baço e nos rins.

\section{DISCUSSÃO}

Trata-se de estudo de necropsia em paciente com hanseníase virchowiana e cardiopatia chagásica crônica com insuficiência cardíaca descompensada grave, apresentando altos níveis séricos de IL-4 e de TNF- $\alpha$. As alterações da pele poderiam corresponder a uma reação reversa (upgrading reaction); entretanto, as características clínicas e o aspecto histopatológico das lesões não permitiram estabelecer esse diagnóstico.

Dados de necropsia em pacientes com hanseníase virchowiana demonstram usualmente comprometimento de órgãos como fígado, baço, testículos, rins e adrenais, além de linfonodos 1724 . Já o acometimento cardíaco nesses pacientes tem sido considerado muito raro5 1014 16; apesar de que a insuficiência cardíaca esteja na lista de causas predisponentes ao óbito nesses pacientes 9 17. Botasso et al. (1993) estudaram os traçados eletrocardiográficos de chagásicos com e sem hanseníase, comparando-os com os de hansenianos nãochagásicos. Apesar da ocorrência de desequilíbrios autonômicos e de alterações eletrocardiográficas semelhantes em ambas moléstias ${ }^{2}$, os autores concluíram pela inexistência de dados indicando que a hanseníase virchowiana pudesse agravar a evolução da cardiopatia chagásica5.

No presente caso, a insuficiência cardíaca teve mau prognóstico, o que difere da evolução descrita como relativamente benigna em hansenianos com doença de Chagas 10; porém, foram evidenciadas alterações cardíacas causadas diretamente por micobactérias e também a presença de ninhos de $T$. cruzi no interior de fibras miocárdicas, fatos estes que poderiam justificar o maior comprometimento das funções miocárdicas e o mau prognóstico da insuficiência cardíaca observados no paciente em questão.

Infiltrados inflamatórios acometendo fibras simpáticas e parassimpáticas, encontrados em casos de hanseníase, podem causar distúrbios cardiovasculares como hipotensão postural e taquicardia em repouso15 1622 . Nos casos com evolução grave como este, com bacteremia ou quadro septicêmico 7 12, freqüentemente 
ocorrem distúrbios metabólicos, desequilíbrios hidroeletrolíticos e ação de toxinas, além da produção aumentada de IL-4, de TNF- $\alpha$ e de óxido nítrico ${ }^{13}$. Em conjunto, esses fatores poderiam inibir respostas inotrópicas e cronotrópicas da estimulação dos receptores beta-adrenérgicos do coração, funcionando como depressores miocárdicos que agravariam a evolução da cardiomiopatia chagásica crônica13 25.

Não há consenso quanto a possíveis repercussões da doença de Chagas na evolução da hanseníase, nos casos de coexistência das duas doenças num mesmo indivíduo. Diniz (1949) sugere que a presença de infecção chagásica em hansenianos possa predispor à disseminação do $M$. leprae 11 , enquanto Dias et al (1970) consideram que a doença de Chagas não afeta a evolução clínica da hanseníase ${ }^{10}$. Entretanto, o aumento da taxa de apoptose de linfócitos T observada na infecção experimental pelo $T$. cruzi e a maior susceptibilidade dos linfócitos Th1 à morte celular programada, além de características genéticas próprias do hospedeiro, poderiam contribuir para o desequilíbrio da relação Th1/Th2, em favor desta última, como demonstrado pelo alto nível de IL-4 neste caso. O favorecimento da resposta imune Th2 e a depressão da resposta Th1 permitem o desenvolvimento de microorganismos intracelulares, como demonstrado no presente caso.

A constatação de esplenomegalia congestiva crônica com infartos esplênicos, além de hipoalbuminemia e depleção linfóide, com teste negativo para HIV, permitiria acrescentar a possibilidade de um papel desempenhado pela subnutrição e fatores associados com a insuficiência cardíaca chagásica 320 21, na imunodepressão observada neste paciente 14 .

\section{REFERÊNCIAS BIBLIOGRÁFICAS}

1. Abbas AK, Lichtman AH, Pober JS. Congenital and acquired immunodeficiencies. In: Abbas AK, Lichtman $\mathrm{AH}$, Pober JS (ed) Cellular and Molecular Immunology. 2nd edition. WB Saunders. Philadelphia. p. 409-430, 1994.

2. Agarwal S, Aggarwal SK. Electrocardiographic changes in multibacillary leprosy. Indian Journal of leprosy. 56:569-574, 1984.

3. Arteaga-Fernández $E$, Pereira Baretto $A C$, lanni BM, Mady C, Lopes EA, Vianna CB, Belloti G, Pileggi F. Trombose cardíaca e embolia em pacientes falecidos de cardiopatia chagásica crônica. Arquivos Brasileiros de Cardiologia 52:189-192, 1980.

4. Bagby Jr GC. Disorders of neutrophil production. In: Bennett JC, Plum F (ed) Cecil Textbook of Medicine. 20th edition. WB Saunders. Philadelphia. p. 908-915, 1996.

5. Botasso OA, Morini JC. Electrocadiographic alterations in lepromatous leprosy patients with concomitant Trypanosoma cruzi infection. International Journal of Leprosy 61:468-471, 1993.

6. Britton WJ. Immunology of leprosy. Transactions of the Royal Society of Tropical Medicine and Hygiene 87:508-514, 1993.

7. Chen TS, Drutz DJ, Whelan GE. Hepatic granulomas in leprosy. Their relation to bacteremia. Archives of Pathology and Laboratory Medicine 100:182-185, 1976.
8. Cunha-Neto E, Gruber A, Zingales B, Kalil J. Estudo da doença de Chagas: abordagem molecular. Revista da Sociedade de Cardiologia do Estado de São Paulo 5:217-229, 1995.

9. Desikan KV, Job CK. A review of postmortem findings in 37 cases of leprosy. International Journal of Leprosy 36:32-44, 1968.

10. Dias JCP, Cunha DA. Hanseníase e doença de Chagas. Estudos realizados no Sanatório São Francisco de Assis, em Bambuí, Minas Gerais. Revista da Sociedade Brasileira de Medicina Tropical 4:31-43, 1970.

11. Diniz O. Lepra e doença de Chagas. Arquivos Mineiros de Leprologia 9:155-171, 1949.

12. Ganapati R, Chulawala RG. Bacteremia in leprosy and its relation to distribution of $M$. leprae in skin. Leprosy in India 48:42-47, 1976.

13. Hare JM, Colucci WS. Role of nitric oxide in the regulation of myocardial function. Progress in Cardiovascular diseases 38:155-166, 1995.

14. Holla VV, Zawar PB, Deshmukh, Sardar SS. Leproma of heart - a case report. Indian Heart Journal 35:111113, 1983.

15. Kale HD, Zawar PC, Chawhan RN, Kulkarni GR. Cardiac dysautonomia in lepromatous leprosy. Indian Journal of Leprosy 56:563-568, 1984.

16. Jayalakshmi P, Looi LM, Lim KJ, Rajogopalan K. Autopsy findings in 35 cases of leprosy in Malaysia. International Journal of Leprosy 55:510-514, 1987. 
17. Katoch K, Ramu G. Cardiovascular involvement in leprosy patients. Japanese Journal of Leprosy 52:73$81,1983$.

18. Launois P. Cytokines et lèpre. Acta Leprologica 8:510, 1992.

19. Lopes MF, Veiga VF, Santos AR, Fonseca MEF, Dos Reis GA. Activation-induced CD4+ T cell death by apoptosis in experimental Chagas'disease. Journal of Immunology 154:744-752, 1995.

20. Oliveira JSM. Tromboses cardíacas e tromboembolismo. In: Cançado JR, Chuster M (ed) Doença de Chagas. $1^{\text {a }}$ edição. Fundação Carlos Chagas. Belo Horizonte. p. 54-60, 1985.

21. Prata A. Chagas' disease. Infectious Disease Clinics of North America 8:61-76, 1994.
22. Radhakrishnan K, Shenoy KT, Kumar B, Kaur S, Khattri HN. Orthostatic hypotension in lepromatous leprosy. Neurology India 26:25-27, 1978.

23. Sampaio EP, Pereira GMB, Pessolani MCV, Sarno EN. Interaction of the leprosy bacillus and the human host: relevant components and mechanism of disease. Journal of the Brazilian Association for the Advancement of Science 46:463-471, 1994.

24. Santino Filho F, Santos VM, Saldanha LF, Henrique $\mathrm{S}$, Brasil MHS. Amiloidose renal secundária a lepra lepromatosa. O Hospital 75:563-570, 1969.

25. Werdan K, Müller-Werdan U. Elucidating molecular mechanisms of septic cardiomyopathy - the cardiomyocyte model. Molecular and Cellular Biochemistry 163-164:291-303, 1996. 